\title{
Análisis de la cesión de créditos en algunos códigos latinoamericanos, con miras a su actualización*
}

\section{Analysis of the Assignment of Credits in Some Latin American Codes, with a View to their Updating}

\author{
Maria Elisa Camacho López ${ }^{\text {a }}$ \\ Universidad Externado de Colombia, Colombia \\ maria.camacho@uexternado.edu.co \\ ORCID: http://orcid.org/0000-0001-5517-6116
}

DOI: https://doi.org/10.11144/Javeriana.vj139.acca

Recepción: 16 Febrero 2017

Aceptación: 04 Julio 2019

Fecha de publicación: 30 Diciembre 2019

\section{Resumen: \\ En los últimos años, la regulación de la cesión de créditos ha sido objeto de importantes cambios al interior de algunos códigos civiles latinoamericanos, en ocasiones como consecuencia del influjo ejercido por experiencias codificadoras foráneas, y en otras por la influencia de los proyectos de armonización y unificación del derecho. Sin embargo, podríamos afirmar, indudablemente, que también es la evolución misma de la figura la que ha conducido a que algunos códigos se separen, en cierta medida, de la disciplina con que inicialmente fue introducida la cesión de créditos en los códigos decimonónicos. En nuestra opinión, estas modificaciones han conducido a su consolidación y actualización, por lo que resulta conveniente evidenciar los cambios que se han producido a la luz de la disciplina tradicional y analizar los aspectos favorables y desfavorables de los mismos.}

Palabras clave: Cesión de créditos, códigos latinoamericanos, pacto de incesibilidad.

\section{Abstract:}

In recent years, the regulation of the assignment of credits has undergone significant changes within some Latin American civil codes, sometimes as a result of the influence of different codified experiences, and some other times by the influence of harmonization projects and unification of laws. However, we can undoubtedly affirm this has been the incorrect evolution of the figure because they have led to some codes being separated, to some extent, from the discipline in which the assignment of credits was initially introduced in the nineteenth-century codes. We believe these modifications have led to their consolidation and updating, so it is convenient to highlight those changes that have occurred in the light of traditional discipline and to analyze the favorable and unfavorable aspects of them.

Keywords: Assignment of credits, Latino American codes, non-assignable credits.

\section{Introducción}

Hemos escogido solo algunos de los códigos civil o civil y comercial vigentes con el fin de abordar el estudio de la cesión de créditos dentro del subsistema jurídico latinoamericano. Adicionalmente, analizaremos los aspectos que consideramos más relevantes para explorar cómo podría lograrse una consolidación y actualización de la figura.

En cuanto a los códigos civiles estudiados, podríamos sugerir una clasificación según el momento de su promulgación. Un criterio temporal nos puede ayudar a dilucidar más fácilmente la forma en que las preocupaciones relacionadas con la cesión del crédito han variado a través del tiempo.

Bajo esta óptica, en el grupo inicial ubicamos los primeros códigos civiles promulgados durante el siglo XIX y todavía vigentes ${ }^{[1]}$. Dentro de este grupo se encuentran el Código Civil chileno ${ }^{[2]}$ y el Código Civil colombiano $^{[3]}$. Por su parte, el Código Civil de Ecuador, aunque fue modificado en el año 2005, e incluso

Notas de autor

\footnotetext{
a Autor de correspondencia. Correo electrónico: maria.camacho@uexternado.edu.co
} 
antes de esto ya había reformado uno de los artículos que regulan la cesión de créditos ${ }^{[4]}$, conserva intacta, por lo demás, la regulación inicial de esta figura, por lo que preferimos dejarlo en este primer grupo ${ }^{[5]}$.

En el transcurso de esta investigación, al hacer alusión al Código Civil chileno, nos estaremos refiriendo también al Código Civil colombiano y ecuatoriano mencionando sus respectivas disposiciones, teniendo en cuenta que los códigos civiles de Colombia y Ecuador comparten prácticamente la misma regulación de la cesión de créditos con el Código Civil chileno (pues la única diferencia está, como lo comentamos antes en el art. 1844 del Código de Ecuador).

Un segundo grupo de códigos son aquellos por medio de los cuales se han derogado los códigos primigenios adoptados durante la primera etapa de codificación, por ende, promulgados durante el siglo XX y aún vigentes. Dentro de este segundo grupo ubicamos el Código Civil de Venezuela ${ }^{[6]}$, el Código Civil de Perú ${ }^{[7]}$ y el Código Civil de Bolivia ${ }^{[8]}$.

El tercer grupo corresponde a los códigos más recientes promulgados durante el siglo XXI y actualmente vigentes.

Se trata del Código Civil de Brasil ${ }^{[9]}$ y el Código Civil y Comercial Unificado de Argentina ${ }^{[10]}$.

\section{Naturaleza jurídica de la cesión de créditos en los códigos latinoamericanos analizados}

Solo en algunos de los códigos civiles latinoamericanos que estudiaremos se consagra una definición de cesión, como en el Código Civil peruano (art. 1.206) y en el actual Código Civil y Comercial Unificado de Argentina (art. 1.614). En otros, en cambio, la definición es obviada, pero del conjunto de normas que regulan la figura y del tratamiento sistemático que se le da a la misma, se puede inferir la naturaleza jurídica que se le atribuye. Así, por ejemplo, en cuanto al tratamiento sistemático que se le da a la figura de la cesión, estas son las elecciones hechas por los codificadores.

En el Código Civil chileno la cesión de derechos está regulada dentro del libro IV relativo a las obligaciones en general y los contratos, en seguida de los títulos dedicados a los contratos de compraventa y de permuta, es decir, en la parte en que son regulados los tipos contractuales.

En el Código Civil de Venezuela la cesión de créditos es regulada en el capítulo VII, ubicado dentro del título V que se dedica al contrato de compraventa.

En el Código Civil de Bolivia la cesión de créditos está regulada en el primer capítulo del título III, relativo a la transmisión de las obligaciones, ubicado a su vez dentro del libro III correspondiente a las obligaciones. Este libro III 'De las obligaciones' se subdivide en dos partes. Una primera parte es sobre las obligaciones en general y se compone de tres títulos, el primero sobre los efectos de las obligaciones, el segundo sobre su extinción y el tercero sobre su transmisión. Dentro de este último hay dos capítulos, el primero sobre la cesión de créditos y el segundo "De la delegación, de la expromisión y de la responsabilidad por tercero".

La segunda parte del libro III está dedicada a las fuentes de las obligaciones, y trata los contratos en general en el título I y los contratos en particular en el título II.

En el Código Civil de Perú, la cesión de créditos está prevista dentro del título VIII sobre la transmisión de las obligaciones, bajo el rótulo de la cesión de derechos, siendo éste su único capítulo.

Por su parte, el título VIII está ubicado dentro de la sección primera dedicada a las obligaciones y sus modalidades, a su vez comprendida dentro del libro VI de las obligaciones. La sección segunda de este mismo libro se refiere a los efectos de las obligaciones, y el libro VII a las fuentes de las obligaciones.

El Código Civil de Brasil le dedica a la cesión de créditos el capítulo I, dentro del título II sobre la transmisión de las obligaciones, a su vez ubicado en el libro I de la parte especial sobre el derecho de las obligaciones. 
En el Código Civil y Comercial argentino, la cesión de créditos, regulada bajo el rótulo de cesión de derechos, es identificada como un tipo contractual, pues se encuentra ubicada dentro del título IV relativo a los contratos en particular, el cual a su vez hace parte del libro III sobre los derechos personales.

Como podemos apreciar el tratamiento sistemático dado a la cesión de créditos varía de un código a otro. En algunos códigos la cesión de créditos es regulada dentro de la parte relativa a los contratos en particular, ya sea como un tipo contractual autónomo, como en el caso del Código Civil chileno y del Código Civil y Comercial argentino; o comprendiéndola dentro del contrato de compraventa, como en el Código Civil venezolano.

La otra elección sistemática es regular la cesión dentro de la parte correspondiente a las obligaciones, más exactamente en lo concerniente a la transferencia de las mismas y no dentro de la regulación de los contratos en particular. En este último grupo están los códigos civiles de Perú, Bolivia y Brasil.

Según nuestra apreciación, el tratamiento de la cesión de créditos dentro de la parte relativa a las obligaciones resulta más adecuado y acorde con su naturaleza jurídica. En primer lugar porque emancipa la cesión de un tipo contractual específico, lo que tiene importantes repercusiones en la figura, como, por ejemplo, reconocer que la misma puede producirse en virtud de cualquier contrato o acto que tenga por objeto la disposición de un crédito, es decir, que puede ser el resultado de una venta, de una donación, de una dación en pago, de una cesión de crédito en garantía, o hacer parte de una operación más compleja como un contrato de factoring o una titularización.

Asimismo, es importante frente al tema de los efectos que produce la cesión, en especial aquel referido a las garantías que derivan de esta, pues, por lo general, la garantía de existencia a cargo del cedente se regula presuponiendo solamente la venta del crédito y no otros negocios que pueden dar lugar a la misma.

\section{La tímida presencia del pacto de incesibilidad en las disciplinas de la cesión de créditos en los códigos latinoamericanos}

Este aspecto no es contemplado en algunas de las codificaciones latinoamericanas aquí analizadas. Por ejemplo, en el Código Civil chileno y, en consecuencia, en el ecuatoriano y colombiano, e igualmente en el Código Civil venezolano, no se encuentra alguna alusión al pacto de incesibilidad.

Obviamente la doctrina ${ }^{[11]}$ y la jurisprudencia ${ }^{[12]}$ no han sido ajenas a esta situación, aunque lo cierto es que la disciplina del negocio de cesión en dichos códigos no contiene ninguna referencia al pacto de incesibilidad. Podríamos conjeturar que ello se debe a la influencia del Code Civil français de 1804, el cual tampoco regulaba el tema, situación que cambió con la Ordenanza 131 del 10 de febrero de 2016 por medio de la cual se reformó el Código Civil francés ${ }^{[13]}$.

En algunos códigos, el pacto de incesibilidad ha sido previsto dentro de las causales que excluyen la cesibilidad de los créditos, constituyendo, por tanto, una excepción al principio general de cesibilidad reconocido por la mayoría de codificaciones. Es el caso del Código Civil de Bolivia (art. 384, y el Código Civil y Comercial argentino (art. 1.616.

El art. 384 del CCBol., bajo el rótulo de noción, hace una descripción del negocio de cesión indicando que el acreedor cedente puede transferir su crédito sin necesidad de que el deudor consienta en ello, siempre que la transferencia no esté prohibida por la ley o por lo convenido con el deudor. Es decir, se plantean dos causales que excluyen la cesibilidad de los créditos, la legal y aquella proveniente del pacto de non cedendo.

Por su parte, el Código Civil y Comercial argentino en su art. 1616, dedicado expresamente al principio de cedibilidad y sus excepciones, consagra, además de la excepción legal y la del pacto de incesibilidad, la excepción que se desprende de la naturaleza misma del crédito.

En el Código argentino derogado también era mencionado el pacto de incesibilidad dentro de las causales que excluían la posibilidad de ceder un crédito (art. 1.444. Por último, hay solo dos códigos en los que, 
además de enunciar el pacto de incesibilidad dentro de las excepciones al principio general, se consagra una situación en la cual dicho pacto no es oponible al cesionario. Se trata, por una parte, del código civil de Perú, cuyo art. 1.210 identificado bajo el rótulo de ineficacia de la cesión establece que esta última no surtirá efectos cuando el crédito cedido es incesible, en virtud de pacto entre las partes del negocio subyacente. Sin embargo, luego agrega que dicho pacto es oponible al cesionario de buena fe en la medida en que haya sido previsto en el instrumento que representa el crédito cedido, o cuando el cesionario haya tenido conocimiento del mismo.

En otras palabras, según el Código Civil peruano la vulneración del pacto de incesibilidad produce la ineficacia de la cesión, a menos que el cesionario de buena fe no haya tenido conocimiento de dicho pacto o no haya podido tener conocimiento del mismo, eventos en los cuales le resulta inoponible.

Asimismo, el Código Civil de Brasil en su art. 286 establece que el acreedor podrá ceder su crédito si a ello no se opone, entre otros, el pacto de incesibilidad con el deudor cedido, aclarando luego que dicho pacto no será oponible al cesionario de buena fe si no consta en el instrumento que representa el crédito cedido. Es decir, se presume que el medio eficaz para que el cesionario tenga conocimiento sobre el pacto de non cedendo sea su colocación en el documento en el que consta el crédito, por lo que, de no haberse reflejado en dicho documento, no podrá ser oponible al cesionario.

Nos llama la atención el hecho de que el Código Civil y Comercial argentino, siendo el más reciente de todos, no haya enunciado expresamente las posibles causas que harían inoponible al cesionario el pacto de incesibilidad, como sí ocurre, en cambio, en los códigos que acabamos de enunciar ${ }^{[14]}$.

De la forma en que se encuentra regulado el pacto de incesibilidad en los códigos latinoamericanos estudiados y de los comentarios hechos por una parte de la doctrina se vislumbra una marcada tendencia a reconocer la validez del pacto de incesibilidad, al tiempo que se observa una convergencia entre los pocos ordenamientos que regulan el pacto de incesibilidad, es decir, los códigos de Bolivia, Brasil, Perú y Argentina, hacia el reproche de la cesión de créditos celebrada en contravención del pacto de incesibilidad con la sanción de la ineficacia.

La primera de ellas tiene que ver con la tendencia mayoritaria a reconocer la validez del pacto de incesibilidad $^{[15]}$. La otra tiene que ver con la concordancia que existe entre los pocos ordenamientos que regulan el pacto de incesibilidad, es decir, los códigos de Bolivia, Brasil, Perú y Argentina, sobre la ineficacia de la cesión de créditos celebrada en contravención del pacto de incesibilidad.

En nuestra opinión, estas dos orientaciones de la mayoría de codificaciones latinoamericanas podrían considerarse una manifestación de apoyo hacia el principio de la autonomía de la voluntad privada, personificada por el pacto de incesibilidad, en contraposición al eventual derecho de libre enajenación de activos $^{[16]}$, el cual estaría representado por las orientaciones que consideran necesario desconocer ese pacto de incesibilidad para dar plena eficacia a la cesión celebrada.

Observamos así un distanciamiento de la mayoría de códigos latinoamericanos respecto de algunos proyectos de armonización y unificación del derecho europeo, que tienden a privilegiar la libre cesibilidad de los créditos eliminando las barreras existentes ${ }^{[17]}$.

Se podría conjeturar que la orientación en los códigos se debe a que la mayoría de estos son civiles, con excepción de las experiencias unificadas de Brasil y Argentina, pues es allí en donde se tipifica la cesión de créditos, mientras que los instrumentos de armonización o unificación, en su mayoría, pretenden regular cesiones de créditos celebradas en el ámbito mercantil. De allí se desprendería otra posible explicación relacionada con la naturaleza de los créditos objeto del negocio de cesión, pues en aquella regulada en los códigos civiles serán comúnmente de naturaleza civil y no comercial, es decir que no resultan de relaciones mercantiles.

Esta podría ser una explicación lógica cuyo ejemplo se veía claramente en el derecho francés, donde el code du commerce (art. L442-6, II, c.) consagraba, dentro del capítulo relativo a las prácticas restrictivas de la 
competencia, la nulidad de las cláusulas que un productor, comerciante, industrial, etc. estipularan dentro de sus contratos, prohibiendo a la otra parte la cesión de los créditos que surgieran de su relación negocial ${ }^{[18]}$.

La naturaleza mercantil de la relación subyacente parece haber sido también uno de los criterios tenidos en cuenta por el legislador colombiano, quien al adoptar la Ley modelo de garantías mobiliarias de la OEA, a través de la Ley 1676 de 2013, previó en el artículo 26 la eficacia de la cesión de créditos en garantía a pesar de la existencia de un pacto de non cedendo. No obstante, llama la atención el hecho de que el legislador peruano, quien también acogió la Ley modelo de garantías mobiliarias de la OEA por medio de la Ley 28.677 del 10 de febrero de 2006 (art. 27, haya optado por separarse en este punto de la ley modelo.

Por el contrario, la mercantilidad de la relación subyacente no parece haber generado alguna razón para distinguir los efectos del pacto de incesibilidad sobre el negocio de cesión en el caso del nuevo Código Civil y comercial argentino, el cual conservó el efecto de la inoponibilidad de la cesión al deudor en virtud del pacto de incesiblidad ${ }^{[19]}$.

Del análisis anterior se desprende la conveniencia de regular las consecuencias derivadas del incumplimiento del pacto de incesibilidad por parte del acreedor cedente, no solo con respecto al negocio de cesión, sino también con respecto a la relación subyacente. Asimismo, es importante regular las excepciones que se pueden reconocer a la ineficacia de la cesión como consecuencia del incumplimiento del pacto de incesibilidad, en especial aquella relacionada con el desconocimiento del pacto por parte del cesionario y a los supuestos que, en cambio, podrían hacer presumir su conocimiento.

\section{Efectos de la cesión de créditos respecto del deudor cedido}

En la cesión de créditos, el deudor, aunque no es parte de la cesión y por ende es identificado como un tercero, no es cualquier tercero ya que en cierta medida le incumbe el contrato celebrado por el acreedor cedente, pues puede resultar afectado como consecuencia del negocio de cesión. Así es como el deudor cedido es identificado como un tercero especial ${ }^{[20]}$.

Lo anterior explica la importancia que tienen las formas empleadas para que la cesión de créditos surta efectos respecto de ese deudor cedido, así como las consecuencias que se desprenden de ello, lo cual analizaremos a continuación.

\section{Notificación o aceptación del deudor cedido para hacerle oponible la cesión}

La notificación de la cesión al deudor cedido o su aceptación, son los medios previstos en los códigos latinoamericanos estudiados para hacer oponible la cesión al deudor cedido. En la mayoría de códigos latinoamericanos, la notificación o aceptación del cedido también sirven para lograr la eficacia de la cesión respecto de los demás terceros y no solo respecto del deudor cedido, es decir que no distinguen entre el medio para hacer oponible la cesión con relación a unos y otros. Es el caso del Código Civil chileno (art. 1.902 ${ }^{[21]}$, del Código Civil y Comercial Unificado de Argentina (art. 1.620, y del Código Civil de Venezuela (art. 1.550 .

Dentro de este grupo podemos ubicar también los códigos civiles de Perú y Bolivia. El Código Civil de Perú porque en su art. 1.215 que regula el inicio de los efectos de la cesión, se refiere de manera expresa y exclusiva al deudor cedido, cuando indica que la notificación o aceptación del cedido son los medios para que la cesión surta efectos. Esto indica que probablemente va a contemplar otra regla para los demás terceros, lo que en realidad no hace. De manera que para el Código Civil de Perú la notificación o aceptación del cedido sirven para que la cesión surta efectos respecto de todos los terceros. 
En cuanto al Código Civil de Bolivia, el art. 389, concerniente a la eficacia de la cesión respecto del deudor cedido, exige la notificación de la cesión al cedido o su aceptación para que la misma surta efectos. Mientras que el art. 390, identificado bajo el rótulo de 'Eficacia de la cesión respecto a terceros', lo que hace en realidad es establecer los criterios que deben ser tenidos en cuenta para resolver la concurrencia entre varios cesionarios de un mismo crédito y no plasma una forma distinta a aquella prevista en el artículo 389 para que la cesión surta efectos respecto del deudor cedido.

Otros códigos, en cambio, distinguen el mecanismo a través del cual se hace oponible la cesión de créditos respecto del deudor cedido y demás terceros. Este es el caso del Código Civil de Brasil cuyo art. 290 establece la notificación al deudor cedido como el medio a través del cual se le hace oponible la cesión, mientras que el art. 288 se refiere a los requisitos para que la cesión surta efectos respecto de los demás terceros, indicando que la misma tendrá que hacerse constar en instrumento público o instrumento particular revestido de las solemnidades previstas en el art. 654.

A estos requisitos se le suma la inscripción en el Registro de títulos y documentos que se debe hacer de los instrumentos de cesión de derechos y de créditos, de subrogación y de dación en pago, conforme a la Ley 6015 de 31 de diciembre de 1973, art. 129, n. ${ }^{\circ} 9$.

En opinión de Barros, la inscripción en dicho registro es necesaria cuando la cesión se hace constar en un documento privado ${ }^{[22]}$.

El motivo por el cual se plantea tal distinción se debe a que los terceros diferentes al deudor cedido, en ocasiones, no tienen manera de saber que el deudor cedido ha sido notificado o ha aceptado la cesión, razón por la cual desconocen la celebración del negocio de cesión, y como consecuencia pueden llegar a desarrollar ciertos actos bajo el entendido de que el cedente sigue siendo el titular del crédito ${ }^{[23]}$.

Estos terceros tienen derecho a conocer sobre el cambio de titular del crédito para evitar actuaciones inútiles, por lo que en principio consideramos apropiado que el medio para hacer oponible la cesión al deudor cedido garantice también el conocimiento de los demás terceros o se fije otra regla para que la cesión surta efectos respecto de estos últimos.

Ahora, en cuanto a la forma en que se debe realizar la notificación de la cesión, o en la que se debe adoptar la aceptación del deudor cedido para que se consideren válidas, estas varían de un código a otro según criterios que tienen que ver con un aspecto más procesal que sustancial.

\section{Reconocimiento de la liberación del deudor cedido}

Una forma de proteger al deudor cedido, teniendo en cuenta que es un tercero respecto del negocio de cesión, es reconociendo su liberación cuando paga al cedente antes de haber recibido la notificación de la cesión o de haberla aceptado.

La mayoría de codificaciones se refieren de manera exclusiva al pago al regular esta liberación. Así pasa, por ejemplo, en el Código Civil de Brasil (art. 292), el Código Civil de Venezuela (art. 1.551 inc. $1^{\circ}$ ) y el Código Civil de Bolivia (art. 391).

Entendido de manera técnica el concepto de pago, como uno de los modos de extinción de las obligaciones, nos parece que la forma en que está regulada dicha liberación es desafortunada, pues llevaría a pensar que el deudor cedido que extingue su obligación de manera diferente al pago respecto del cedente, antes de recibir la notificación de la cesión o de haberla aceptado, no quedaría liberado.

Esta última interpretación sería errónea, más aún teniendo en cuenta que, desde el punto de vista práctico, la liberación consiste en el hecho de que el deudor cedido puede oponer al cesionario la excepción del pago de su obligación y comprobándose que el mismo se efectuó antes de haber recibido la notificación o de haberla aceptado, tendrá lugar la liberación comentada; por lo que habría de predicarse lo mismo respecto de los demás modos de extinguir las obligaciones. 
En nuestra opinión, la razón por la cual se ha incurrido en esta deficiente formulación, tiene que ver con el efecto adverso que en algunas legislaciones se le asigna al conocimiento del deudor cedido sobre el negocio de cesión, cuando siendo anterior a la recepción de la notificación de la cesión o de su aceptación, evita la liberación del deudor si éste le paga al cedente. Esta regla tiene como principal antecedente el art. 1264 del Codice Civile italiano, en cuyo inciso segundo se establece que antes de la notificación el deudor que paga al cedente no se libera de su obligación con respecto al cesionario si este último demuestra que el deudor tenía conocimiento de la cesión.

Ahora bien, aunque la aplicación de esa norma ha sido extendida a través de algunas interpretaciones doctrinarias y jurisprudenciales a otros modos de extinguir las obligaciones diferentes del pago, en opinión de algunos autores esa interpretación extensiva no tendría lugar, pues el conocimiento del deudor cedido no se equipara a la notificación o aceptación de la cesión ${ }^{[24]}$.

En otras palabras, al deudor que tuvo conocimiento de la cesión antes de la notificación o aceptación de la misma, y que extinguió su obligación por un medio distinto del pago, no se le aplica la norma prevista en el artículo 1264 del Codice Civile italiano. Así ha quedado planteado en el Código Civil de Perú (art. 1.216 y en el Código Civil de Bolivia (art. 391.

Por las razones anteriores consideramos preferible la redacción de la liberación del deudor cedido en los términos previstos en el Código Civil y Comercial argentino (art. 1621, pues, en primer lugar, no se limita la liberación del deudor cedido al pago, sino que se refiere a la extinción de la obligación a través de cualquiera de los modos de extinguir las obligaciones; y, en segundo lugar, fija como criterio para dicha liberación la ausencia de notificación o aceptación de la cesión ${ }^{[25]}$.

Ahora, en cuanto a los efectos que produce el conocimiento del deudor cedido respecto del pago hecho antes de recibir la notificación de la cesión, nos parece conveniente su inserción como excepción a la liberación contemplada, pero siempre teniendo en cuenta que dicho conocimiento no se debería equiparar a la notificación o aceptación de la cesión y que, por tanto, su efecto debería limitarse, aquí sí, al pago de la obligación.

\section{Excepciones oponibles}

En esta materia no se han presentado grandes modificaciones a su regulación, tal vez debido a que este aspecto depende de manera intrínseca de la naturaleza misma de la cesión como sucesión particular del crédito. Más aún, es probable que la dependencia de la regulación de las excepciones oponibles a la naturaleza de la cesión, sea la razón para que algunos ordenamientos obvien la cuestión. Tal es el caso del código civil de Perú y del código civil de Venezuela, los cuales no contienen ninguna norma dedicada expresamente a mencionar las excepciones oponibles dentro de la disciplina de la cesión. Aunque sí contienen una disposición relativa a la excepción de compensación dentro de la regulación correspondiente a este modo de extinguir las obligaciones $^{[26]}$.

En el Código Civil y Comercial de Argentina, este aspecto se encuentra regulado en el art. 1.621, y a diferencia del código anterior (art. 1474 no excluye expresamente el ejercicio de la excepción de compensación cuando la cesión fue aceptada de manera pura y simple.

Llama la atención la ausencia de una norma en ese sentido, pues observamos cómo en los demás códigos se conserva, dentro de la disciplina de la cesión o en la parte correspondiente a la compensación como modo de extinguir las obligaciones, un artículo que establece las reglas por las que se regirá la oposición de la compensación en la cesión de créditos.

Así, por ejemplo, en el Código Civil de Brasil el artículo 294 indica que el deudor podrá oponer al cesionario las excepciones que le conciernen como las que en el momento de tener conocimiento de la cesión tenía en contra del cedente. Por su parte, el artículo 377 del mismo código regula la excepción 
de la compensación dentro de las normas que regulan la compensación, como una forma de extinguir las obligaciones. Igualmente, el Código Civil chileno (art. 1.906) ${ }^{[27]}$ y el Código Civil de Bolivia (art. 388), contienen un artículo relativo a las excepciones oponibles dentro de la disciplina de la cesión.

En dichas normas se indica que el deudor cedido podrá oponer al cesionario todas las excepciones que tenía en contra del cedente, con exclusión de las excepciones de carácter personal, las cuales no podrá oponer al cedente. Por su parte la regulación de la excepción de compensación está contenida dentro de la regulación correspondiente a este modo de extinguir las obligaciones ${ }^{[28]}$.

\section{Garantías}

Tradicionalmente se han distinguido dos especies de garantías en el régimen de la cesión de créditos. Por una parte, la denominada garantía de existencia del crédito cedido y por otra, la garantía de solvencia del deudor cedido.

En cuanto a la garantía de existencia, hay dos aspectos relevantes que deben ser abordados. El primero de ellos tiene que ver con su procedencia, la cual, por lo general, se hace depender del título bajo el cual se celebra la cesión, razón por la que algunas codificaciones regulan de manera distinta la garantía de existencia según se trate de una cesión a título oneroso o a título gratuito. Así es en el Código Civil de Brasil (art. 295) y en el Código Civil de Bolivia, en este último se prevén dos normas distintas para cada tipo de cesión: el artículo 392 para la cesión a título oneroso y el artículo 393 para la cesión a título gratuito.

En otros códigos, al regular la garantía de existencia a cargo del cedente, se manifiesta su consideración bajo la órbita solamente de la cesión a título oneroso. Así ocurre, por ejemplo, en el Código Civil y Comercial Unificado de Argentina (art. 1.628) y en el Código Civil chileno (art. 1.907) ${ }^{[29]}$.

Un tercer grupo está conformado por aquellos códigos que al regular la garantía de existencia no hacen referencia al título en virtud del cual se cede el crédito. Es el caso del Código Civil peruano (art. 1.212) y el Código Civil de Venezuela (art. 1.553), aunque en este último caso es del todo evidente que el título es la compraventa, pues recordemos que la cesión del crédito se encuentra regulada dentro de la disciplina del contrato de compraventa.

Esta diferencia, aunque parece sutil y tal vez inocua, no lo es tanto, pues la regulación de la garantía de existencia bajo el presupuesto de la onerosidad del título de la cesión ha suscitado la inquietud sobre su aplicación o no a las cesiones a título gratuito.

Por ejemplo, Arturo Valencia Zea ${ }^{[30]}$ afirma que en el derecho colombiano las cesiones a título gratuito no dan lugar a la responsabilidad del cedente por la existencia, como tampoco por la solvencia del deudor cedido, mientras que Fernando Hinestrosa ${ }^{[31]}$ prefiere atenuar la rigidez de la postura anterior sosteniendo la inaplicación de la garantía de existencia en el caso de una donación gratuita (art. 1.479 CC.Col), pero reconociendo al mismo tiempo dos excepciones a esta regla general en aquellos eventos en los que el donante está obligado a garantizar el saneamiento por evicción. Como, por ejemplo, cuando se trata de una donación con causa onerosa en la que el donante conoce la ajenidad de la cosa (art. 1480 CC.Col.), o cuando se está en presencia de una donación remuneratoria (art. 1492 CC.Col.).

En el derecho argentino también se ha presentado la misma reflexión, incluso bajo el código derogado (art. 1484).

En efecto, en opinión de López de Zavalía, cuando la cesión es gratuita, en principio, el cedente no responde para con el cesionario ni por la existencia del crédito cedido ni por la solvencia del deudor, pero esto debe ser leído a tenor de lo normado por el art. 2157 del código derogado, según el cual a la evicción de "derechos cedidos gratuitamente, o por remuneración de servicios o por cargas impuestas en la cesión, es aplicable lo dispuesto sobre las donaciones de esas clases" ${ }^{\text {[32] }}$. 
En vigencia del actual código, aunque algunos autores sostienen sin ambages la inaplicación de la garantía de existencia a las cesiones a título gratuito ${ }^{[33]}$, otros se plantean la necesidad de distinguir ese efecto según el tipo de acto gratuito ${ }^{[34]}$.

La incertidumbre generada alrededor de la aplicación o no de la garantía de existencia a ciertas clases de cesiones no nos parece deseable, pero al ser ineludible la dependencia que existe entre las garantías a cargo del cedente y el título del cual se desprende la cesión, consideramos por ello que sería conveniente adoptar un listado más amplio y detallado que abarque las garantías a cargo del cedente, independientemente del título bajo el cual se celebre la cesión, aunque el mismo tenga carácter supletorio respecto de las normas que regulan las mismas garantías para el título originario de la cesión.

De este primer aspecto concerniente a la procedencia o no de la garantía de existencia según el título en virtud del cual se celebra la cesión, se desprende la cuestión sobre las excepciones a la exigibilidad de dicha garantía. Así pues, nótese cómo en algunos códigos la exigibilidad de la garantía de existencia a cargo del acreedor cedente no se hace depender solamente de si la cesión es a título oneroso o gratuito, sino también de la buena o mala fe del cedente, a semejanza de la regulación prevista en algunos proyectos de unificación del derecho de los contratos, más concretamente con el Código Europeo de los Contratos.

Así, por ejemplo, en el Código Civil de Brasil (art. 295 la mala fe del cedente lo hace responsable de la garantía de existencia del crédito cedido, aunque la cesión haya sido celebrada a título gratuito. En el Código Civil y Comercial de Argentina, la mala fe del cedente es tenida en cuenta para exigir su responsabilidad por la garantía de solvencia (art. 1628, como también para establecer los efectos económicos de la garantía de existencia (art. 1.629.

El segundo aspecto que en nuestra opinión merece especial atención tiene que ver con lo que comprende la garantía de existencia, debido a que la mayoría de codificaciones establecen de manera un poco vaga que el cedente responde por la existencia o por la exigibilidad del crédito cedido, pero hay situaciones que podrían resultar dudosas frente a dicha formulación tan amplia.

Bajo esta óptica, sería conveniente aprovechar los estudios de los proyectos de armonización para formular un listado en el que se comprendan algunas de las situaciones en virtud de las cuales puede llegar a operar la garantía de existencia. Así se podrían comprender la inexistencia de la relación jurídica de la cual supuestamente nació el crédito cedido, la extinción de dicha relación jurídica antes de la cesión, las causales de ineficacia que llegaren a afectar de manera definitiva el negocio subyacente, la titularidad del cedente, entre otras, cuya introducción requeriría un análisis previo.

En cuanto a la garantía de solvencia, lo primero que debemos advertir es que, en la mayoría de codificaciones, ésta requiere un acuerdo expreso entre las partes de la cesión, es decir, se trata de un elemento accidental del negocio. Así se prevé en el CCBr (art. 296, CCyCoArg. (art. 1630, CCCh (art. 1907³5], CCPer (art. 1213, y CCVen (art. 1554.

Solo el Código Civil de Bolivia establece la posibilidad de que la garantía de solvencia opere, además que, por el acuerdo expreso entre las partes, naturalmente, cuando la insolvencia fuese pública y anterior a la cesión. Este tipo de garantía por insolvencia es comúnmente conocida como garantía de insolvencia de derecho, por desprenderse de la regulación de la figura y no requerir un acuerdo entre las partes.

Dentro de los ordenamientos que la prevén se encuentran el Código Civil español (art. 1529, el Código Civil mexicano (art. 2043 y estaba prevista en el Código Civil argentino derogado (art. 1476.

A su vez, esta regla tiene su origen en un antecedente común a estas tres codificaciones, que es el Proyecto de Código Civil de García Goyena de 1851, en el que fue adoptada una disposición que hacía responsable al cedente por la insolvencia anterior y pública del deudor cedido. Es muy probable que de estas experiencias jurídicas el codificador boliviano haya tenido en cuenta la del Código Civil español, el cual también sirvió como fuente para la elaboración de ese código.

Ahora, esta garantía de insolvencia se refiere a la imposibilidad de cumplir la prestación por parte del deudor cedido, y ello se puede identificar, en ocasiones, con la ausencia de bienes para el pago del importe al que está 
obligado, o pensemos, por ejemplo, en el deudor comprometido a una obligación de hacer para cuya ejecución requiere una maquinaria que ya no tiene al momento de la cesión.

En el caso de la insolvencia de derecho ésta debe ser anterior y pública. Por anterior se entiende que debe ser previa o concomitante al momento en que viene celebrado el negocio de cesión para que pueda ser exigible al acreedor cedente ${ }^{[36]}$.

Por su parte, la publicidad de la insolvencia ha sido interpretada de varias formas. A juicio de algunos autores aquello que se consagró por insolvencia pública fue la insolvencia conocida por todos, es decir aquella conocida tanto por el cedente como también por el cesionario del crédito ${ }^{[37]}$.

No obstante, dicho concepto de publicidad parece errado, razón por la cual algunos juristas consideran más adecuado entender que donde se ha dicho "pública" se ha querido decir conocida por uno u otro de los contratantes, de tal forma que la responsabilidad del cedente vendedor tendrá lugar cuando la insolvencia sea pública para él o, con más exactitud, que sea conocida por él, mientras que desaparece su responsabilidad cuando es conocida por el cesionario, sin importar si era conocida por el cedente $\mathrm{e}^{[38]}$.

En opinión de otros juristas, la publicidad de la insolvencia exige algo más que un simple conocimiento general o un rumor público de ésta, razón por la cual afirman que la ley alude a la insolvencia que ya ha tenido estado judicial. En otras palabras, de conformidad con esta postura el requisito de publicidad de la insolvencia exige la presencia de hechos que revelen con publicidad suficiente la insolvencia del deudor cedido, tales como serían el concurso, la quiebra o cualquier otra sentencia de la que se pueda determinar ese estado del deudor cedido $^{[39]}$.

Algunos autores objetan a la precedente interpretación el hecho de ser demasiado restrictiva y dejar al margen muchos supuestos evidentes de insolvencia que no han sido objeto de declaración judicial. Además, consideran que una hipótesis en la cual el cesionario está dispuesto a adquirir un crédito de un deudor cuyo estado de insolvencia ha sido declarado de alguna forma es poco probable, razón por la cual la responsabilidad en cuestión no tendría lugar ${ }^{[40]}$.

Como podemos apreciar, no es tarea fácil determinar el contenido de los requisitos exigidos por la ley para la operatividad de la garantía por la insolvencia anterior y pública a cargo del cedente. Igualmente, llama la atención el hecho de que esta garantía de insolvencia de derecho haya sido abandonada por la nueva codificación civil y comercial de Argentina, lo que nos conduce a interrogarnos sobre su verdadera utilidad o pertinencia dentro de la disciplina de la cesión.

\section{Conclusiones}

A lo largo de este estudio hemos tratado de identificar las novedades que presentan las codificaciones latinoamericanas más recientes, respecto de las primeras codificaciones decimonónicas. Dicho análisis ha sido muy interesante pues hemos podido observar un verdadero desarrollo de la figura, lo que en nuestra opinión demuestra la vigencia de la cesión de créditos.

Sin embargo, dentro de esos cambios hay algunos que parecen más convenientes que otros, o que tal vez se acomodan de mejor forma a unos principios jurídicos que a otros, razón por la cual, a continuación, enunciaremos algunas de las modificaciones que consideramos más oportunas, en especial respecto de nuestro Código Civil colombiano.

- En primer lugar, en cuanto a la sistemática de la figura, sería conveniente un cambio de la misma en aquellos códigos donde aún se encuentra regulada dentro del título relativo a los contratos en especial, pues ratificaría la posibilidad de que se desprenda de cualquier título o relación jurídica subyacente. Además, resultaría más acorde con la naturaleza jurídica de la misma si se incluyera dentro del título de las obligaciones en general, como lo hacen algunos códigos civiles latinoamericanos. 
- En cuanto al pacto de incesibilidad, consideramos importante su tratamiento dentro de la disciplina de la cesión de créditos, indicando, principalmente, los efectos que produce respecto del negocio de cesión y las posibles excepciones que se pueden predicar de dicho efecto general.

- Dentro del tema de la liberación del deudor cedido por el pago efectuado a persona distinta del verdadero acreedor, nos parece que sería importante hacer alguna referencia a los efectos que produce el conocimiento del deudor cedido, especificando las características que dicho conocimiento debe tener para que se le endilguen los efectos previstos.

- Finalmente, otro tema que merece una profunda revisión es el de las garantías a cargo del acreedor cedente, pues se trata del principal efecto que se desprende de la cesión, razón por la cual la certeza sobre aquello que cubre de acuerdo con la causa de la cesión resulta adecuada. Además, sería conveniente tener una regulación más uniforme con relación al tema de la garantía de solvencia.

\section{Bibliografía}

Alejandro Guzmán Brito, La Codificación civil en Iberoamérica siglos XIX y XX, Ed. jurídica de Chile (2000).

Arturo Alessandri, Manuel Somarriva \& Antonio Vodanovic, Tratado de las obligaciones, III, Ed. jurídica de Chile, (2004).

Arturo Valencia Zea, Derecho civil, III, Temis, (1990).

Carlos A. Hernández \& Julieta B. Trivisono, Comentario a la Cesión de Derechos, en Código Civil y Comercial de la Nación Comentado, 9-58 (Ricardo Luiz Lorenzetti, Rubinzal-Culzoni eds., 2015).

Código Civil Boliviano [CCBol]. Decreto Ley 12760 de 1875. Arts. 384, 391, 392, 393. 6 de julio de 1975 (Bolivia).

Código Civil de Brasil [CCBr]. Ley 10.406 de 2002. Arts. 286, 288, 290, 292, 294, 295, 296, 654, 1972.10 de enero de 2002 (Brasil).

Código Civil y Comercial Unificado de la Nación [CCCUN]. Ley 26拥94 de 2014. Arts. 1614, 1616, 1620, 1621, 1628, 1629, 1630.7 de octubre de 2014 (Argentina).

Código Civil de Chile [CCCh]. Ley de 14 de diciembre de 1855. Arts. 1659, 1902, 1905, 1906, 1907. 1 de enero de 1857 (Chile).

Código Civil Colombiano [CCC]. Ley 57 de 1887. Arts. 1844, 1960, 1479,1480, 1492, 1718, 1960, 1963, 1964, 1965. 15 de abril de 1887 (Colombia).

Código Civil (Ecuador) [CCE]. Codificación 2005-010. Arts. 1675, 1842, 1844, 1846, 1847, 1848. 21 de noviembre de 1857 (Ecuador).

Código Civil Francés [CCFr]. Ley del 21 de marzo de 1804. Arts. 1321, L442-6, II, c. 21 de marzo de 1804 (Francia). Código Civil Italiano [CCI]. Decreto del 16 de marzo de 1942, n. ${ }^{\circ} 262$. Art. 1264. 16 de marzo 1942 (Italia).

Código Civil del Perú [CCPe]. Ley 295 del 4 de julio de 1984. Arts. 1206,1212, 1213, 1215, 1216, 1292. 24 de julio de 1984 (Perú).

Código Civil de Venezuela [CCVen]. Ley de Reforma Parcial del Código Civil de Venezuela. Arts. 1161, 1337, 1550, $1551,1553,1554.26$ de Julio de 1982 (Venezuela).

Fernando Hinestrosa, Tratado de las obligaciones, Ed. Universidad Externado de Colombia (2002).

Fernando López de Zavalía, Teoría de los Contratos, II (Fernando López de Zavalía ed., 1985).

Giovanni Finazzi, La Cessione del Credito, en Trattato delle Obbligazioni (Alessi Rosalba y Mannino Vincenzo eds., Ed. CEDAM, 2008).

José Joaquín Ugarte Godoy, El Contrato de factoraje y la probibición convencional de ceder créditos a un factor, 97 Revista de Derecho y Jurisprudencia de Chile, n. ${ }^{\circ}$ 2, 65-80 (2000). https://doctrina.vlex.cl/vid/factoraje-convencional -ceder-factor-227066441

José Luis Navarro Pérez, La cesión de créditos en el derecho civil español, Ed. Comares (1988).

I José María Manresa, Comentarios al Código Civil español, cap. X, Ed. Reus (1969).

Juan Larrea Holguín, Manual elemental de derecho civil del Ecuador, Ed. Corporación de estudios y publicaciones (2005). 
Marcela Viano Carlomagno, Comentario a la Cesión de Derechos, en Código Civil y Comercial de la Nación Comentado, 322-333 (Marisa Herrera, Gustavo Carmelo y Sebastián Picasso eds., Ed. Infojus, 2015).

María Elisa Camacho López, La cesión de créditos en los proyectos de armonización y unificación del derecho de los contratos, 16 Revista e-mercatoria, n. ${ }^{\circ}$ 2, 3-43, (2017). https://doi.org/10.18601/16923960.v16n2.01

Philippe Malaurie \& Laurent Aynès, Droit Civil: les obligations, Ed. Defrénois (2007).

Quinto Mucius Scaevola, Código Civil, cap. XXIII, Ed. Reus (s.a.).

René Abeliuk Manasevich, Las Obligaciones, cap. II, Ed. jurídica de Chile (1993).

Sandro Schipani, Codici Civili nel Sistema latinoamericano, en Digesto delle discipline privatistiche, Sezione Civile, 286-319 (Ed. Utet, 2010).

Sebastián Justo Cosola, Comentario a la cesión de derechos, en Código Civil y Comercial de la Nación comentado, 167-171 (Julio César Rivera y Graciela Medina eds., Ed. La Ley, 2014).

IV Washington De Barros Monteiro, Curso de direito civil, (39 ed., Ed. Saraiva, 2003).

\section{Notas}

* Artículo de investigación. Este artículo es resultado de la línea de investigación en “Cesión de créditos”, perteneciente al Grupo de investigación de derecho comercial colombiano y comparado de la Universidad Externado de Colombia.

[1] Este primer grupo de códigos tenían como objetivo primordial la realización de la independencia de los países latinoamericanos. Ver Sandro Schipani, Codici Civili nel Sistema latinoamericano, en Digesto delle discipline privatistiche, Sezione Civile, 286-319, Ed. Utet (2010).

[2] El Código Civil chileno fue elaborado por Andrés Bello, aprobado mediante Ley del 14 de diciembre de 1855, en vigor a partir del $1^{\circ}$ de enero de 1857 hasta la actualidad. Es considerado uno de los grandes códigos de América Latina ya que fue acogido con algunas modificaciones por Ecuador y Colombia.

[3] La adopción del Código Civil chileno en Colombia se produjo de manera gradual. En un primer momento ésta tuvo lugar en algunos de los estados que conformaban la Confederación Granadina. Posteriormente hacia 1866 el Código de Bello, acogido como código de Cundinamarca con ciertas modificaciones, regía en casi todos los estados, los cuales a partir de 1863 conformaron los Estados Unidos de Colombia. Luego, durante la presidencia de Manuel Murillo Toro, se presentó la iniciativa de adoptar el Código de Bello en todos los territorios nacionales y fue así como en 1873 fue aprobado el Código del Estado de Santander, que era el Código Civil chileno con algunas modificaciones. Finalmente, en virtud de la Constitución de 1886, en la que Colombia adoptó una forma unitaria de gobierno, se dispuso la entrada en vigor del Código Civil de la Nación sancionado el 26 de mayo de 1873. Este era, como lo indicamos antes, el Código del Estado de Santander, es decir, el Código Civil chileno, y cuya vigencia se mantiene en la actualidad, cfr. Alejandro Guzmán Brito, La Codificación civil en Iberoamérica siglos XIX y XX, Ed. jurídica de Chile, 395 (2000).

[4] Se trata del art. 1844 el cual fue modificado por el art. 237 (3) de la Ley 107 de 1998, publicada en registro oficial 367 del 23 de julio de 1998. A su vez, esta disposición fue sustituida por disposición reformatoria quinta, numeral 23 del Código Orgánico General de Procesos. En este artículo se especifica la forma en que debe hacerse la notificación del crédito de acuerdo con la naturaleza del mismo, y de acuerdo con la operación que da lugar a la cesión, indicando una regla precisa para el caso de la cesión que se efectúa como consecuencia de una titularización.

[5] El Código Civil chileno fue acogido por la Corte Suprema de Justicia de Ecuador, a la cual se le había asignado la labor de elaborar un código civil para su país. Ésta le hizo algunas modificaciones mínimas y presentó el proyecto al Senado y a la Cámara, siendo aprobado el 21 de septiembre de 1857, promulgado luego en 1860, entrando en vigor el $1 .^{\circ}$ de enero de 1861 . Recientemente, en el año 2005, fue modificado y éste es el código vigente en la actualidad.

[6] Según nos informa Sandro Schipani, op. cit., 300, el primer Código Civil que tuvo Venezuela en 1862 fue derogado por el Código Civil de 1873, el cual, a su vez, fue sustituido formalmente en 1881, en 1896, 1904, 1916, 1922, 1942 y 1982 . Aunque, en opinión del autor, éstas han sido reformas, más que verdaderos y propios códigos. El Código de 1873 asumió como base el Código Civil italiano de 1865, el cual a su vez fue elaborado teniendo muy presente el Código Civil francés, aunque con algunas modificaciones. Dentro de las reglas del Código Civil francés adoptadas por el Código Civil venezolano está la eficacia real del contrato, prevista en el art. 1.161 del CCVen.: "En los contratos que tienen por objeto la trasmisión de la propiedad u otro derecho, 
la propiedad o derecho se trasmiten y se adquieren por efecto del consentimiento legítimamente manifestado; y la cosa queda a riesgo y peligro del adquirente, aunque la tradición no se haya verificado".

[7] El Código Civil peruano vigente fue promulgado el 24 de julio de 1984 e inició su vigencia a partir del 14 de noviembre de ese mismo año. Este Código derogó el anterior de 1936, el que a su vez derogó el primer Código Civil peruano de 1852.

[8] El Código Civil de Bolivia vigente fue promulgado el 6 de julio de 1975, entrando en vigor a partir del 2 de abril de 1976. Éste derogó el código de 1831, el cual ya había sido modificado en varios aspectos. Cfr. Sandro Schipani, op. cit., 313, quien además comenta que en la redacción del Código de 1976 se tuvo en cuenta el Código Civil italiano de 1942.

[9] Entre los códigos civiles latinoamericanos más recientes se encuentra el de Brasil, el cual fue aprobado el 10 de enero de 2002 y entró en vigor el 10 de enero de 2003.

[10] Este código fue promulgado el 7 de octubre de 2014 y entró a regir el 1.o de agosto de 2015.

[11] En Chile, los autores Arturo Alessandri, Manuel Somarriva \& Antonio Vodanovic, Tratado de las obligaciones, III, Editorial jurídica de Chile, 18 (2004), comentan al respecto: “También las partes pueden acordar que el crédito derivado de un contrato no sea cedible. Aunque nuestro Código civil no lo dice, en virtud del principio de la autonomía de la voluntad, no hay inconveniente para insertar semejante cláusula”. En la doctrina colombiana, Arturo Valencia Zea, comenta: “c) Finalmente, los contratantes pueden pactar que el acreedor no cederá su crédito, y como esta estipulación es válida, pues nada tiene de contrario a las buenas costumbres o al orden público, el crédito adquiere la calidad de no cedible. Sin embargo, las partes pueden posteriormente derogar su estipulación” Arturo Valencia Zea, Derecho civil, III, Temis, 395 (1990). En doctrina ecuatoriana Juan Larrea Holguín, Manual elemental de derecho civil del Ecuador, Ed. Corporación de estudios y publicaciones, 178 (2005) expresa al respecto: "En segundo lugar, los individuos pueden dar carácter intransferible a ciertos derechos que constituyen o conceden a otros. El principio de libertad contractual permite que las partes interesadas asignen el carácter de intransferibles a los derechos o créditos en general”.

[12] A diferencia de la doctrina, la jurisprudencia es realmente escasa. En efecto, hasta el momento solo conocemos un fallo proferido por la Corte Suprema de Justicia de Chile del 6 de agosto de 1909, comentado por José Joaquín Ugarte Godoy, El Contrato de factoraje y la probibición convencional de ceder créditos a un factor, 2 Revista de Derecho y Jurisprudencia de Chile, 65-80 (2000), quien sobre el mismo explica: “(...) la Corte Suprema declaró que valía la convención que prohibía la cesión de un crédito, y que tal estipulación no desnaturalizaba el derecho de dominio, si bien el asunto sub lite no era una acción de nulidad de la enajenación ni una acción resolutoria o de perjuicios por transgresión del pacto", aunque valga la pena aclarar que para Ugarte las prohibiciones convencionales de enajenar, sean estas absolutas o relativas, son contrarias al sistema legal chileno.

[13] En efecto, la Ordenanza 2016-131 del 10 de febrero de 2016 modificó el artículo 1321 del Código Civil francés, el cual prevé en su último inciso: "Le consentement du débiteur n’est pas requis, à moins que la créance ait été stipulée incessible", que traduce "El consentimiento del deudor no es requerido, a menos que el crédito haya sido estipulado como incesible" (traducción de la autora). En nuestra opinión, de la norma transcrita se puede inferir que para el legislador francés el pacto de incesibilidad de un crédito es válido y que la consecuencia de su vulneración por parte del acreedor cedente consiste en la ineficacia de la cesión respecto del deudor cedido, a menos que dicho deudor otorgue su consentimiento a la cesión.

[14] A pesar de ello, la doctrina parece estar de acuerdo con que el pacto de incesibilidad debe estar contenido en el título que, a su vez, contiene el crédito cedido o que, incluso, de llegar a pactarse con posterioridad al negocio subyacente, debe ser conocido por los terceros a dicho negocio, pues de lo contrario será inoponible. Cfr. Carlos A. Hernández \& Julieta B. Trivisono. Comentario a la Cesión de Derechos, en Código Civil y Comercial de la Nación Comentado, 9-58 (Ricardo Luiz Lorenzetti, Rubinzal-Culzoni eds., 2015).

[15] Ver supra nota 12. En contra de la posición mayoritaria en la doctrina chilena: José Joaquín Ugarte Godoy, supra, 80. Por su parte debemos advertir que, en la doctrina argentina, en vigencia del código derogado, tal como lo explican Carlos A. Hernández \& Julieta B. Trivisono, op. cit., 26, se planteó el interrogante sobre la posibilidad de pactar la intransferencia de un crédito en forma absoluta, pues en opinión de algunos autores tendrían que aplicarse a la cesión los límites establecidos para la compraventa, mientras que otros sostienen que las normas de la cesión son especiales y por tanto no serían aplicables los principios establecidos en esa materia. En el actual código, ese debate se produce como consecuencia del art. 1972 del Código Civil y Comercial argentino en virtud del cual se establece la nulidad de la cláusula general de inenajenabilidad en los actos a título oneroso, mientras que en los negocios a título gratuito se permite la cláusula de incesibilidad por un plazo máximo de diez años. Ver también: Marcela Viano Carlomagno, Comentario a la Cesión de Derechos, en Código Civil y Comercial de la Nación Comentado, 322-333, (Marisa Herrera, Gustavo Carmelo y Sebastián Picasso eds., Ed. Infojus, Ciudad autónoma de Buenos Aires (2015). 
[16] Nos referimos aquí a un posible derecho a la libertad de enajenación de activos porque nos parece que sostener su presencia, por lo menos en el ordenamiento jurídico colombiano, requiere una investigación adicional, pues a simple vista no entrevemos la posibilidad de que un pacto de incesibilidad pueda considerarse una vulneración de ese supuesto derecho.

[17] Sobre la cesión de créditos en los proyectos de armonización y unificación del derecho, ver: María Elisa Camacho López. La cesión de créditos en los proyectos de armonización y unificación del derecho de los contratos, 16 Revista e-mercatoria, n. ${ }^{\circ}$ 2, 3-43 (2017).

[18] El contenido de dicha disposición era: "II. - Sont nuls les clauses ou contrats prévoyant pour un producteur, un commerçant, un industriel ou une personne immatriculée au répertoire des métiers, la possibilité: c) D'interdire au cocontractant la cession à des tiers des créances quiil détient sur lui" que traduce "II. - Son nulas las cláusulas o contratos en las que un productor, un comerciante, un industrial o una persona matriculada en el repertorio de oficios, prevea la posibilidad: c) De prohibir a la otra parte la cesión a terceros de los créditos detentados respecto de aquel" (Traducción de la autora). Sin embargo, esta norma fue modificada por la Ordenanza 359 del 24 de abril de 2019, la cual ya no contiene esa prohibición.

[19] Según los comentarios estudiados sobre el art. 1616 del Código Civil y Comercial argentino, el criterio que generaría un trato diferenciado del pacto de incesibilidad dependerá de la gratuidad u onerosidad de la relación subyacente de la que surge el crédito cedido.

[20] La categoría de terceros en la cesión de créditos comprende diversos sujetos, los cuales podríamos distinguir de acuerdo con su mayor o menor interés en los efectos producidos por el negocio de cesión. Así, podríamos hablar de unos terceros absolutos respecto de los cuales el negocio de cesión no surte ningún efecto y, además, no poseen interés alguno en los efectos que está llamada a producir la cesión. Una segunda categoría de terceros que podríamos denominar relativa, está conformada por todos aquellos sujetos que, no habiendo intervenido en la regulación de la cesión, como tampoco en el negocio jurídico que ha dado origen al crédito objeto de transferencia, tienen algún interés en los efectos producidos por la cesión. Dentro de esta especie de terceros se encuentran los otros cesionarios del mismo crédito, cuando este último ha sido objeto de varias cesiones, como también los acreedores del cedente y del cesionario para quienes no es indiferente si el crédito es del cedente o del primer cesionario. Por último, hallamos un tercero que podríamos denominar especial o principal, quien es el deudor cedido en la medida en que se trata de un tercero que en ocasiones puede participar al negocio de cesión, pero además quien definitivamente hacía parte del negocio que dio origen al crédito objeto de transferencia. Sobre este tercero recaerá el efecto principal de la cesión, el cual es el de la transferencia del crédito del cedente al cesionario, razón por la que no cabe duda sobre el interés que el deudor cedido tiene sobre los efectos de la cesión, en la medida en que de ellos depende que realice un pago válido o no, cfr. Giovanni Finazzi, La Cessione del Credito, en Trattato delle Obbligazioni, 111(Alessi Rosalba y Mannino Vincenzo eds., Ed. CEDAM, 2008); Philippe Malaurie \& Laurent Aynès, Droit Civil: les obligations, 399 (2007).

[21] Código Civil de Colombia (art. 1960), Código Civil de Ecuador (art. 1842).

[22] Cfr. IV Washington De Barros Monteiro, Curso de direito civil, (39 ed., Ed. Saraiva, 2003).

[23] Cfr. René Abeliuk Manasevich, Las Obligaciones, cap. II, Ed. jurídica de Chile, 868 (1993).

[24] Cfr. Giovanni Finazzi, op. cit., 402.

[25] En el caso del art. 1905 del Código Civil de Chile (artículos 1963 del CCCol. y 1846 del CCEc.), aunque no alude al conocimiento del deudor cedido, también se refiere exclusivamente al pago.

[26] Así, por ejemplo, en el Código Civil de Perú dicha norma es el art. 1292 y en el Código Civil de Venezuela el art. 1337.

[27] Código Civil de Colombia (art. 1964), Código Civil de Ecuador (art. 1847).

[28] CCCh. (art. 1659), CCCol. (art. 1718), CCEc. (art. 1675), CCBol. art. 371

[29] Código Civil de Colombia (art. 1965), Código Civil de Ecuador (art. 1848).

[30] Cfr. Arturo Valencia Zea, op. cit., 400.

[31] Cfr. Fernando Hinestrosa, Tratado de las obligaciones, Universidad Externado de Colombia, 435 (2002).

[32] Cfr. Fernando López de Zavalía, Teoría de los Contratos, II, 601 (Fernando López de Zavalía ed., 1985).

[33] Cfr. Sebastián Justo Cosola, Comentario a la cesión de derechos, en Código Civil y Comercial de la Nación comentado, 797-814, (Julio César Rivera y Graciela Medina eds., Ed. La Ley, Ciudad Autónoma de Buenos Aires, (2014)., 812: "no hay evicción 
si no existe onerosidad o al menos, contraprestación medible o equiparable económicamente — caso de la cesión- permuta. Se descarta entonces la garantía de evicción a las transmisiones gratuitas de derechos o créditos”.

[34] En este sentido hay quienes sostienen: "Sin embargo, cabe tener en cuenta que, si la cesión fue gratuita, pero con la imposición de un cargo o bien fue realizada con carácter remuneratorio, se aplicarán supletoriamente las normas de los artículos 1556 y 1557 que establecen la responsabilidad del donante por evicción” Cfr. Carlos A. Hernández \& Julieta B. Trivisono, op. cit., 55.

[35] Código Civil de Colombia (art. 1965) y Código Civil de Ecuador (art. 1848).

[36] Cfr. José Luis Navarro Pérez, La cesión de créditos en el derecho civil español, Comares, 198 (1988), quien considera innecesaria la precisión planteada por Quinto Mucius Scaevola, conforme a la cual no puede decirse realmente que la insolvencia sea anterior sino coetánea a la cesión. Navarro afirma que se entiende que el legislador con esta expresión quiso indicar una insolvencia que permanece al momento de la cesión, lo que sostiene es acorde con la naturaleza misma de la insolvencia la cual corresponde a un estado duradero cuya generación y mantenimiento no es inmediata ni espontánea.

[37] Cfr. Quinto Mucius Scaevola, Código Civil, cap. XXIII, Ed. Reus, Madrid, 943, (s.a.).

[38] Id., 945.

[39] Cfr. I José María Manresa, Comentarios al Código Civil español, cap. X, Ed. Reus, 574 (1969).

[40] En este sentido, véase José Luis Navarro, op. cit., 199.

\section{Licencia Creative Commons CC BY 4.0}

Para citar este artículo/To cite this article: Camacho López, María Elisa, Análisis de la cesión de créditos en algunos códigos latinoamericanos, con miras a su actualización, 68 Vniversitas, n. ${ }^{\circ} 139$ (2019). https://doi.or g/10.11144/Javeriana.vj139.acca 